Supplement of Atmos. Chem. Phys., 14, 8749-8761, 2014

http://www.atmos-chem-phys.net/14/8749/2014/

doi:10.5194/acp-14-8749-2014-supplement

(C) Author(s) 2014. CC Attribution 3.0 License.

(c) (i)

Atmospheric

Chemistry

and Physics

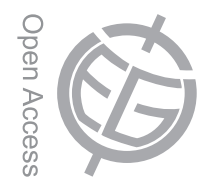

Supplement of

\title{
Investigation of the "elevated heat pump" hypothesis of the Asian monsoon using satellite observations
}

M. M. Wonsick et al.

Correspondence to: R. T. Pinker (pinker@atmos.umd.edu) 


\section{Supplements}

\section{List of Figures}

Figure S1. Monthly mean GPCP precipitation in July for the years $2001-2012$ over the region bounded by $5^{\circ} \mathrm{N}$ to $40^{\circ} \mathrm{N}$ and $50^{\circ} \mathrm{E}$ to $100^{\circ} \mathrm{E}$.

Figure S2. TOMS aerosol index for May of the years used in the study by Lau et al. (2006).

High absorbing aerosol years are shown in top row and low aerosol years are shown in bottom row.

Figure S3. TOMS aerosol index for May of the years used in the study by Lau et al. (2006).

High absorbing aerosol years are shown in top row and low aerosol years are shown in bottom row (as available from http://gdata1.sci.gsfc.nasa.gov/daacbin/G3/gui.cgi?instance_id=toms using the NASA Giovanni tool, provided by Goddard Earth Sciences Data and Information Services Center (GES DISC)). 


\section{Supplements}
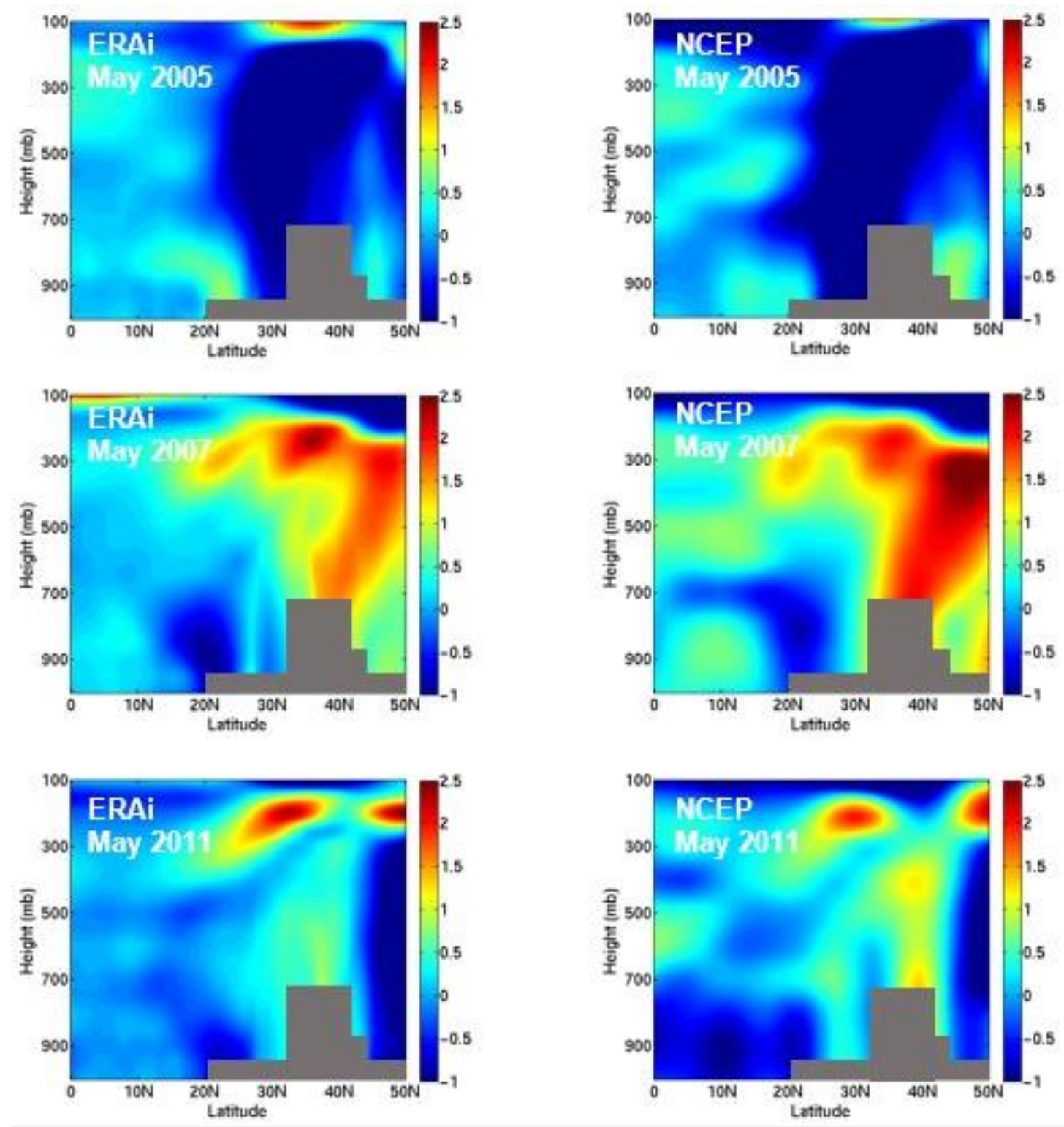

Figure S1. Latitude-height distribution of temperature anomaly $\left({ }^{\circ} \mathrm{C}\right)$ from ERAi and (left column) ג NSEF/DOE-R2 Reanalysis (right column) over latitude sector $70 \mathrm{E}^{\circ}$ to $100^{\circ} \mathrm{E}$ for May of the low aerosol years: 2005 (top), 2007 (middle), 2011 (bottom). Gray shaded area is an idealized representation 

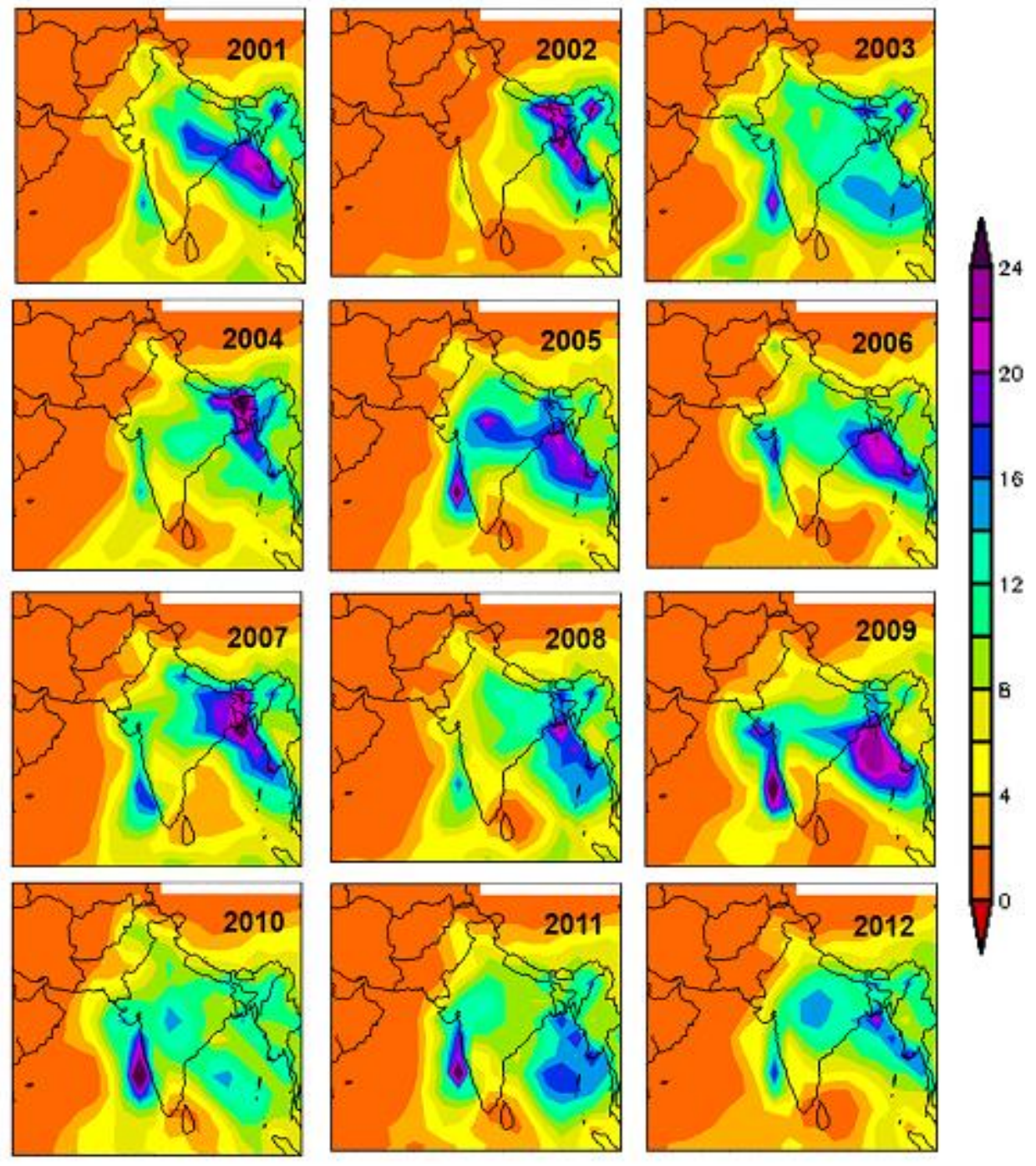

Figure S2. Monthly mean GPCP precipitation in July for the years $2001-2012$ over the region bounded by $5^{\circ} \mathrm{N}$ to $40^{\circ} \mathrm{N}$ and $50^{\circ} \mathrm{E}$ to $100^{\circ} \mathrm{E}$. 


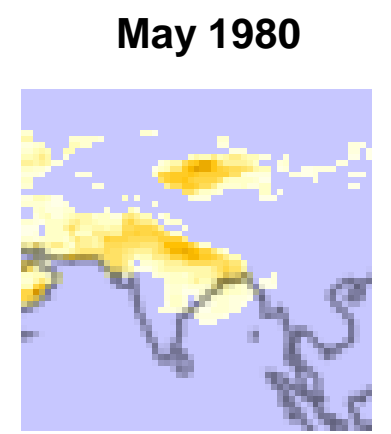

May 1982

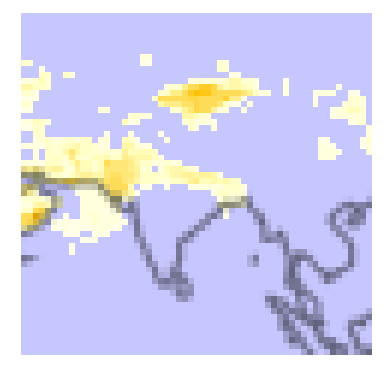

May 1985

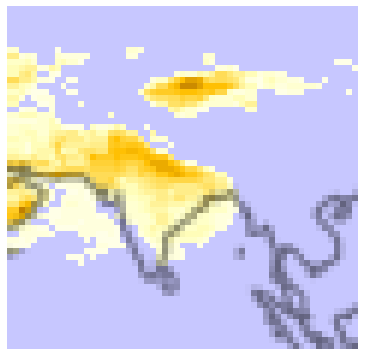

May 1983

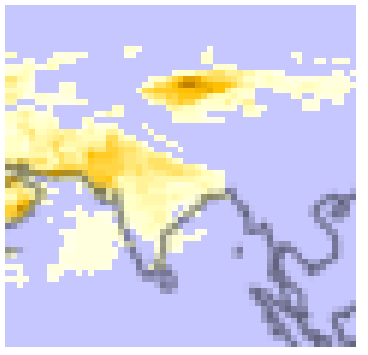

May 1988

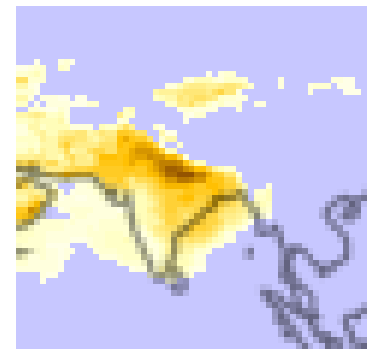

May 1990

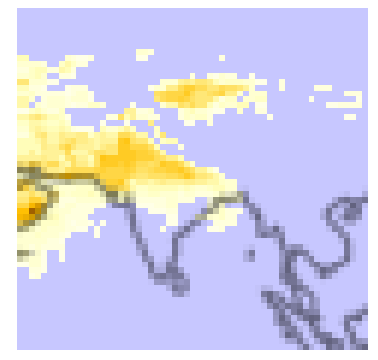

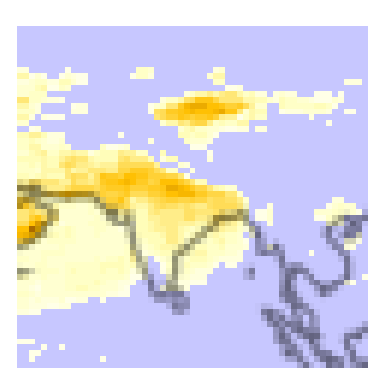

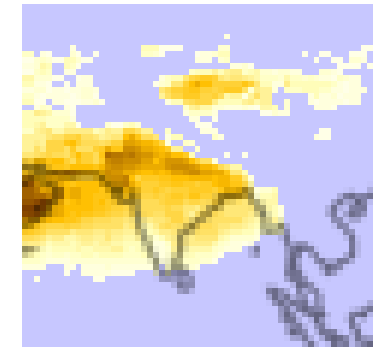

May 1992

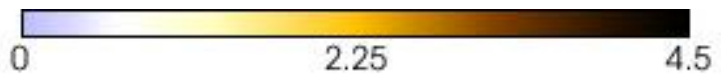

Figure S3. TOMS aerosol index for May of the years used in the study by Lau et al. (2006).

High absorbing aerosol years are shown in top row and low aerosol years are shown in bottom row. 